\title{
Consideraciones sobre el comercio de libros en Lima a principios del siglo XVII
}

\author{
Carlos Alberto González Sánchez
}

Universidad de Sevilla

\begin{abstract}
El estudio de la circulación libraria en la América colonial continúa siendo un tema poco explotado, contrastando con el auge de las investigaciones sobre bibliotecas particulares o de instituciones de enseñanza. Las razones, muy diversas, vienen determinadas por la escasez de fuentes, entre las que destacan los inventarios de mercaderes libreros, cuya información es indispensable para el conocimiento de las inquietudes lectoras y, en definitiva, de los esquemas mentales de la sociedad de la Edad Moderna. En esta ocasión, dos interesantes inventarios de mercancía libraria, negociada en Lima a principios del siglo XVII, nos ofrecerán algunos indicios de una faceta crucial de la vida humana: libros y lecturas.
\end{abstract}

\section{Introducción}

Un importante sector de la emigración al Nuevo Mundo en los siglos XVI y XVII, deseoso de fortuna y ante el escaso margen de acción laboral encontrado, terminó ejerciendo en el comercio. Normalmente, para el común de los inmigrantes la solución estuvo en un tráfico menor, casi siempre de carácter ambulante, en las ciudades y pueblos de indios del Nuevo Continente, ${ }^{1}$ quedando el comercio de cierta envergadura para los cualificados profesionalmente.

Mercaderes de todo tipo hubo en Indias; pero, dejando a un lado los estratos superiores, vinculados a las élites sociales, ${ }^{2}$ la mayor parte de ellos no ejercían en un ramo concreto, vendían lo que podían adquirir según su capacidad económica y de negocio: telas, quincallería, utillaje, menaje doméstico, productos de la tierra, libros, etc.; no obstante, el mundo comercial del libro parece que requirió una cierta especialización y expe-

1 Estudié una muestra de este tipo de mercaderes, en el virreinato del Perú, en mi tesis doctoral: Dineros de ventura: la varia fortuna de la emigración a Indias (siglos XVI-XVII), Sevilla, 1995.

2 Sobre la importancia de la actividad mercantil de las oligarquías americanas se han realizado investigaciones importantes, de las que vamos a destacar la de Hoberman, L.S.: "Merchants in seventeenth-century Mexico city: a preliminary portrait", Hispanic American Historical Review, 3, Durham, 1977, págs. 479-503; Peña, J.F. de la: Oligarquía y propiedad en Nueva España. 1550-1624, México, 1983; para el caso peruano son muy sugerentes, a título de ejemplos, las de Bronner, F.: "Elite formation, in seventeenth-century Perú", Boletín de Estudios Latinoamericanos y del Caribe, 24, Amsterdam, 1978, págs. 3-26; y el más reciente de Ramírez Horton, S.: Patriarcas provinciales. La tenencia de la tierra y la economía del poder en el Perú colonial, Madrid, 1991. 
riencia. Aunque mercachifles y tratantes ofertaban almanaques, devocionarios, estampas o literatura de cordel lo mismo que otras menudencias, un negocio mayoritario, o exclusivo, en torno al impreso, ya fuera ambulante o estable, no se adecua al mínimo de formación cultural de aquellos aventureros.

\section{Los mercaderes}

Cuando el historiador del Antiguo Régimen tiene la suerte de toparse con el inventario de la mercancía de un librero o de un impresor, agradece el hallazgo enormemente, antes que nada porque su fiabilidad para la historia de la lectura ofrece menos limitaciones que los inventarios post mortem de particulares, los cuales se limitan a registrar, sin más, una serie de libros hallados entre las propiedades del difunto, que pudieron ser objeto de lectura o no. ${ }^{3}$ En cambio, y aunque tampoco carezca de inconvenientes, el contenido de los documentos de mercaderes de libros responde a los cálculos de la demanda, a lo que se sabe que va a ser vendido y, por tanto, derivado de los gustos lectores o de lo que está a bien poseer y aceptado en la comunidad donde se vive. Pero además, y como ya resaltara R. Chartier, porque, entre mediados del siglo XV y comienzos del XIX, la actividad tipográfica estaba sometida al capital comercial; los mercaderes libreros, aparte de intervenir en otras áreas de influencia no menos importantes, dominan a los maestros impresores y controlan el mercado desarrollando la librería de surtido. ${ }^{4}$

En esta ocasión, fruto de la investigación que realicé con los Bienes de Difuntos, voy a analizar dos inventarios de mercaderes de libros españoles que negociaban en Lima durante el primer tercio del siglo XVII. En la fecha, la capital del virreinato peruano había alcanzado la fisonomía propia de un gran centro cultural, el más importante del Nuevo Mundo, contando con universidad, imprenta y un importante número de clérigos, funcionarios y profesionales que promocionaban el mercado de lecturas de la ciu-

3 Las limitaciones sobre las fuentes y metodología de la historia de la lectura han sido magistralmente expuestas por Chartier, R.: El orden de los libros. Lectores, autores y bibliotecas en Europa entre los siglos XIV y XVIII, Barcelona, 1994, págs. 23-41. Al caso concreto de los inventario ye me referí en mi trabajo: "Los libros de los españoles en el virreinato del Perú. Siglos XVI y XVII", Revista de Indias, LVI, 206, Madrid, 1996, págs. 7-47.

4 Chartier, R.: Libros, lecturas y lectores en la Edad Moderna, Madrid, 1993, pág. 27. 
dad, según Leonard, de mayores dimensiones que el existente en muchas medianas y pequeñas localidades españolas. ${ }^{5}$

Los dos mercaderes pueden ser casos representativos de emigrantes lanzados a la aventura con la intención de hacer fortuna a través de un ramo comercial tan sugerente y útil para el mejor conocimiento del perfil mental de la sociedad colonial. ${ }^{6}$ De sus vidas y personalidad es poco lo que he podido averiguar, pues las noticias insertas en las fuentes empleadas no complacen del todo la curiosidad del investigador. ${ }^{7}$ Uno y otro tenían por nombres Pedro Durango de Espinosa y Cristóbal Hernández Galeas.

Pedro Durango de Espinosa nació en Jemenuño, localidad de la actual provincia de Segovia, en la que su padre era sacristán y escribano. Hacia 1570, más o menos, se casó con una tal Isabel, dotada con 1.000 ducados en tierras de viñas, mujer con la que tuvo dos hijos, Francisco y Magdalena. Más tarde la familia se instala en Úbeda, donde Pedro abrió una tienda para vender libros, especiería y mercería ${ }^{8}$ o sea, estaba vinculado al pequeño comercio de libros antes de emigrar. No sabemos qué motivos le impulsaron, hacia 1580, a tomar la decisión de pasar a Indias sin su mujer e hijos, aunque todo parece indicar que lo hiciera para probar fortuna en un ramo mercantil más o menos conocido, alentado por las noticias de abultados beneficios y buenas oportunidades del negocio. Al final de su vida lo encontramos en Lima, ciudad en la que era conocido como Pedro Flecher y donde moriría en 1603, siendo enterrado, amortajado con el hábito de San Francisco, en la capilla de San Juan del convento de Santo Domingo.

5 Leonard, I. A.: Los libros del conquistador, México, 1979, pág. 240.

6 No es mucha la bibliografía existente sobre impresores y libreros españoles en Indias y sus actividades económicas, concretamente para el Perú podemos citar el trabajo de Hampe Martínez, T.: "Presencia de un librero medinense en Lima (Siglo XVI)", Revista Histórica, XXXIX, Lima, 1988, págs. 103-112; para Nueva España Grañén Porrúa, M. ${ }^{a}$ I.: "El ámbito socio-laboral de las imprentas novo-hispanas. Siglo XVI”, Anuario de Estudios Americanos, XLVIII, Sevilla, 1991, págs. 49-94; y el excelente estudio de Griffin, C.: The Crombergers of Seville: the history of a printing and merchant dinasty, Oxford, 1988.

7 Los documentos los hemos obtenido de los Autos de Bienes de Difuntos, institución encargada de inventariar y trasladar a España los bienes, convertidos en numerario, de los españoles fallecidos en Indias sin herederos, para así hacerlos llegar a sus sucesores. Dichos expedientes forman una serie en la Sección de Contratación del Archivo General de Indias. Véase mi tesis doctoral: Dineros de ventura...

8 Esta circunstancia, de libreros que a la vez negociaban con mercería, ropas o ganado, fue bastante generalizada en las pequeñas y medianas localidades de la España del Antiguo Régimen, pues era difícil vivir exclusivamente de la venta de libros. Véase Rojo Vega, A.: "Los grandes libreros españoles del siglo XVI y América”, Cuadernos Hispanoamericanos, 500, Madrid, 1992, páginas 115-131. El autor también analiza los negocios que grandes mercaderes de libros castellanos realizaron con el continente americano. 
En los documentos no hay mención de establecimiento concreto en el que Pedro Durango ejerciera su trabajo y, por ello, podríamos estar hablando de un tratante o bien de un factor de un comerciante de mayor rango. Ahora bien, el hecho de permanecer solo en Indias, unos 25 años, sin casa ni local que sepamos, y estar compuesta su hacienda por bienes fácilmente transportables, ropas y menaje, 4 esclavos y 3 mulas, que le ayudarían en el negocio, me inclina hacia la primera opción, es decir, un mercader ambulante, sin residencia, estable que no ha tenido la oportunidad de asentarse en un local concreto de alguna ciudad del virreinato, hecho que habría condicionado la llegada de su familia.

En el inventario, previo a la almoneda, que los jueces de los bienes de difuntos hicieron de las pertenencias de Pedro Flecher constan 1.197 libros y "dos prensas con sus yngenios para el oficio", artefacto este último que pudo haber empleado en el arte de la impresión o la encuadernación, pues, como se verá, tenía obras sin encuadernar. Una vez vendida su hacienda en pública subasta - los libros a otro mercader por 409 pesos-,${ }^{9}$ los oficiales reales de la Audiencia procedieron a la repatriación de 2.039,5 pesos, depositados en la Casa de la Contratación en 1606. El numerario iba dirigido a su mujer e hijos, a quienes Pedro dejó como herederos legítimos en el testamento que dictó antes de morir en Lima. ${ }^{10}$

A Cristóbal Hernández Galeas lo conocemos peor, entre otras razones porque murió abintestato. Sabemos que nació en Extremadura, concretamente en Jerez de los Caballeros. La muerte repentina de este personaje, y las averiguaciones que hicieron los oficiales del Juzgado de Bienes de Difuntos, nos aclaran algo más de su vida. Una mañana del mes de diciembre de 1619 lo hallaron muerto en una tienda que tenía alquilada en la calle de los ropavejeros de Lima, junto a la Iglesia Mayor, habitáculo que le servía de vivienda. Por ello, cuando le hicieron inventario sólo hallaron ropas, un colchón, algo de menaje y mercancía compuesta de 1.763 libros y miles de estampas de imágenes, rosarios y crucifijos de bronce. Subastados dichos bienes, la mercadería, como ocurrió con la de Flecher, adquirida por otro comerciante a cambio de 500 pesos, pagadas las deu-

9 He aquí un dato interesante, testimonio de como los libreros, o particulares, se surtían de impresos, a buen precio, en las almonedas de difuntos, y de otras perspectivas de la circulación del libro. Estas prácticas cotidianas de la población frente a los libros las destaca Peña Díaz, M.: "Los encantes y la circulación del impreso en la Barcelona del siglo XVI", Estudis Castellonencs, 6, Castellón, 1994-1995, págs. 1047-1056. $273, \mathrm{r}^{\circ} 3$.

10 La documentación sobre Pedro Durango de Espinosa se encuentra en AGI, Contratación, 
das y satisfechos los gastos de entierro y funeral, se enviaron a España 3.627 pesos, llegados a Sevilla en $1620 .{ }^{11}$

Cristóbal Hernández era un mercader de cajón, poco más que un tratante o mercachifle y con unas circunstancias sociovitales muy parecidas a las del anterior, dedicado también a la venta, aunque de forma complementaria, de ropas y quincallería. En una declaración de testigo, para averiguar datos personales del difunto, se dice que su tienda era un cajón, o lo que es lo mismo, un local portátil de madera que los mercaderes itinerantes solían instalar en las plazas y alrededores de las ciudades, una modalidad muy extendida en el mundo colonial. ${ }^{12}$ Por tanto, estamos frente a ese comercio menor de las Indias que tantas posibilidades abrió a los emigrantes españoles, fueran mercaderes o no. La realidad comercial del Nuevo Mundo, basada en monopolios, dejó escaso margen de acción a los comerciantes de menor volumen de negocios. Si bien, y aunque no sea el caso de los nuestros, la condición de mercachifle no es forzosamente equiparable a un nivel económico bajo, pues los hubo que hicieron grandes fortunas. ${ }^{13}$

\section{La mercancía}

De entrada destaca el volumen de libros inventariados: 2.930, 1.197 y 1.763 respectivamente, una cantidad nada despreciable y de una estimación más alta según el perfil de los mercaderes en estudio. No obstante, será conveniente saber cuál es la línea temática que ofertaban, variable que nos llevará a otras conclusiones. Si empezamos con la mercancía de Pedro Durango, salta a la vista una apreciación de interés: el 88,4\% (1.058) de sus libros corresponden a temas laicos, mientras que tan sólo el 11,6\% (139) son de contenido religioso. Estos porcentajes invierten la tendencia de lo que suele ser habitual: el predominio abrumador de la temática reli-

11 AGI, Contratación, 345A, r. ${ }^{\circ} 11$.

12 A. Rojo Vega también destaca esta modalidad de libreros ambulantes en las ferias castellanas, que vendían los libros en tiendas portátiles de madera: "Los grandes libreros españoles...". En Indias estos tratantes disputaban el negocio a tenderos y comerciantes de los consulados, con los que mantuvieron enconadas luchas; véase Iwasaki, F.: "Ambulantes y comercio colonial: iniciativas mercantiles en el virreinato peruano", Jahrbuch Für Geschichte von Staat Wirtschaft und Gesellschaft Lateinamerikas, 24, Colonia, 1987, págs. 179-211.

13 Un ejemplo es el estudiado por Lohmann Villena, G.: Les Espinosa, une famille d'hommes d'affaires en Espagne et aux Indes à l'époque de la colonisation, París, 1968. 
giosa. ${ }^{14}$ En principio, las cifras podrían indicar una cierta especialización de la mercancía ofertada y no el efecto inmediato de la demanda; pero dejemos estas consideraciones para más adelante.

La composición temática resulta del modo siguiente:

\section{Estructura temática. Inventario de Pedro Durango}

\begin{tabular}{lcc}
\multicolumn{2}{c}{ LAICA } & \\
Temática & N. $^{\circ}$ Libros & \% Sobre total \\
\hline Literatura & 156 & 13 \\
Historia & 753 & 63 \\
Clásicos & 14 & 1,1 \\
Ciencia & 18 & 1,5 \\
Jurídica & 4 & 0,3 \\
Gramática & 50 & 4,1 \\
Música & 14 & 1,1 \\
Política & 5 & 0,4 \\
Varios & 58 & 4,8
\end{tabular}

Hagiografía

Espiritual

Cristo y Virgen

Escolástica

Varios

\section{RELIGIOSA}

\begin{tabular}{crr} 
& 14 & 1,1 \\
& 58 & 4,8 \\
& 11 & 0,9 \\
& 7 & 0,5 \\
& 35 & 2,9 \\
\cline { 2 - 2 } Total: & 1.197 & 100
\end{tabular}

14 Esta tendencia, en torno al 75\% la proporción de la temática religiosa, suele ser la norma en las investigaciones sobre los libros de la época y así lo he puesto de relieve en una investigación sobre 444 inventarios postmortem de españoles residentes en el virreinato del Perú: "Los libros de los españoles...". Un porcentaje similar también obtuve en el estudio de una muestra de registros de navíos que contenían libros como mercancía: "El libro y la Carrera de Indias: registros de ida de navíos", Archivo Hispalense, 220, Sevilla, 1989, págs. 93-103. Otras muestras significativas, en la misma línea, son las de Griffin, The Cromberger...; Guibovich, P.: "Libros para ser vendidos en el virreinato del Perú a fines del siglo XVI”, Boletín del Instituto Riva-Agüero, 13, Lima, 1984, págs. 85-114; Hampe Martínez, Teodoro: "The diffusion of books and ideas in colonial Perú: a study of private libraries in the sixteenth and seventeenth centuries", Hispanic American Historical Review, 73, Durham, 1993, págs. 211-233; y Kropfinger von Kügelgen, H.: "Exportación de libros europeos de Sevilla a la Nueva España en el año de 1586", en Los libros europeos en la Nueva España a fines del siglo XVI, Wiesbaden, 1973, págs. 26-105. 
La literatura laica está compuesta por 9 apartados, mientras que el capítulo religioso sólo consta de 5. Por tanto, la primera, además de contar con un volumen mucho mayor de libros, también está más diversificada. El apartado de historia y literatura representan el 76\% (909 libros) del total, una tendencia que no suele ser la normal en las bibliotecas de la época que conocemos, en las que resulta prioritario, condicionado por la estructura socioprofesional dominante, gramática, jurisprudencia, política y clásicos. ${ }^{15}$ Por su parte, entre los libros de contenido religioso sobresalen los géneros espiritual y hagiográfico.

Cristóbal Hernández tenía en su tienda al tiempo de morir 1.763 libros, de los que el 58,2\% (1.026) corresponden a temas religiosos y el $41,8 \%$ (737) a laicos. La distancia entre los dos bloques no es de una dimensión abultada, prácticamente se igualan, pero esta vez la religiosa aparece con una diversificación mayor.

Estructura temática. Inventario de Cristóbal Hernández RELIGIOSA

\begin{tabular}{lcc} 
Temática & $N^{\circ}{ }^{\circ}$ Libros & \% Sobre total \\
\hline Sermones & 11 & 0,6 \\
Cánones & 12 & 0,6 \\
Patrística & 16 & 0,9 \\
Hagiografía & 70 & 4 \\
Espiritual & 495 & 26,8 \\
Oración & 74 & 4,2 \\
Cristo y Virgen & 12 & 0,6 \\
Pastoral & 190 & 11 \\
Bíblica & 63 & 3,6 \\
Teología moral & 28 & 1,6 \\
Escolástica & 10 & 0,5 \\
Varios & 45 & 2,6
\end{tabular}

Continúa en pág. siguiente

15 Véase un reciente estado de la cuestión en Hampe Martínez, T.: Bibliotecas privadas en el mundo colonial, Frankfurt, 1996. 


\title{
Estructura temÁtica. Inventario de CRistóbal HeRnÁndeZ (continuación)
}

\author{
LAICA
}

\begin{tabular}{|c|c|c|}
\hline Temática & N. ${ }^{\circ}$ Libros & $\%$ Sobre tota \\
\hline Gramática & 199 & 11,4 \\
\hline Ciencia & 13 & 0,7 \\
\hline Jurídica & 4 & 0,2 \\
\hline Literatura & 425 & 24,5 \\
\hline Clásicos & 47 & 2,7 \\
\hline Historia & 28 & 1,6 \\
\hline \multirow[t]{2}{*}{ Varios } & 21 & 1,2 \\
\hline & 1.763 & 100 \\
\hline
\end{tabular}

De la clasificación anterior destacan los bloques de espiritual y creación literaria, ambos representan el 54\% del total; por tanto, podemos obtener unas conclusiones similares a las deducidas del inventario de Pedro Durango. Resta señalar que Cristóbal Hernández también dedicaba parte de su negocio a la venta de estampas de imágenes sagradas y otros objetos devocionales (rosarios y crucifijos), una situación muy común entre los mercaderes de libros y acorde a la tan extendida demanda, en auge desde Trento, de una sociedad sacralizada como la de los siglos XVI y XVII. En este caso, el documento recoge un total de 8.024 estampas y cientos de rosarios y pequeños crucifijos de bronce.

Centrándonos ahora en el estudio de los autores y títulos aparecidos en los inventarios, sin perder de vista las dificultades a la hora de identificarlos, comenzando por el de Pedro Durango, los libros de historia componen el capítulo numéricamente más importante; sin embargo, de los 753 registrados, 585 sólo constan como libros de historia de diferentes autores sin ninguna otra especificación, por lo que no podemos saber de qué obras se trata y esto limita las apreciaciones del análisis.

Entre los títulos de historia representativos están 72 ejemplares de los Varones ilustres de Indias, 13 Historias de señoría, 12 de Isabel reina de Inglaterra, 12 de la Crónica del rey don Pedro, 10 de la Campaña de Roma, 9 de la Historia troyana, 9 de Carlos duque de Borgoña, 5 de la Historia del Gran Capitán y 5 de la Historia de los jarifes. En menor proporción, no más 
de 3 ejemplares, la Historia de los reyes godos, Las Navas de Tolosa, la Historia General, la Historia del rey don Rodrigo, Historia de las Indias y el Monserrate de Cristóbal de Virués. En general se trata de unas obras cuyo contenido responde al relato de hazañas épicas, a modo de novelas de aventuras. Al respecto, T. Dadson observa como España enviaba al Nuevo Mundo libros de entretenimiento y ficción, recibiendo a la par historias y relatos de la conquista. ${ }^{16}$ En efecto, muy escasas son las crónicas o historias de las Indias encontradas, al contrario de lo que ocurre con la ficción.

En el apartado de literatura, las novelas de caballería casi completan el capítulo con 97 ejemplares, dando pruebas de la persistencia de su popularidad a principios del siglo XVII, fecha en la que, en teoría, habían sido sustituidas por la afición a otros géneros. ${ }^{17}$ Este capítulo de ficción está representado por sus creaciones más difundidas: 27 Florisel de Niquea, 12 Floranís de Castilla, 10 Palmerín de Oliva, 9 Amadís de Gaula, 9 Sergas de Esplandián, 8 Selidón de Iberia, 5 Lisuarte, 4 Amadís de Grecia y 4 del Caballero Asisio. ${ }^{18}$ Aparte del género caballeresco destacan títulos emblemáticos de la épica renacentista: 12 del Orlando furioso y 1 del Orlando enamorado de Ariosto, 2 de la Araucana de Ercilla y 2 Lusíadas de Camoens. En otra faceta, 9 de la Primera parte del honesto y agradable entretenimiento de damas y galanes de Juan Francisco Corbacho.

En la gramática, otro de los apartados voluminosos, es de notar la presencia de 48 ejemplares del habitual Arte de la lengua castellana de Antonio de Nebrija, uno de los libros más difundidos en la América hispana. ${ }^{19}$ Por lo demás, dentro de la temática laica, figuran clásicos grecolatinos como 3 de la República de Aristóteles, 4 de Lucano, 2 de las Fábulas de Esopo; César, Séneca, Cicerón, Homero, etc.; libros científicos, pocos y con predominio de la medicina, entre ellos: 5 de Valles de Covarrubias, 4 de la Historia de la medicina de Sevilla, 3 del Tractado de las drogas y medicinas de las Indias Orientales... de Cristóbal de Acosta y uno de Nicolás Monardes. También son escasas materias como la jurídica, de la

16 Dadson, T.: "Libros y lecturas sobre el Nuevo Mundo en la España del Siglo de Oro", Histórica, XVIII, Lima, 1994, págs. 1-26.

17 Para un estudio detenido sobre la novela de caballería y su significación en la sociedad colonial remitimos a Leonard: Los libros...

18 Todavía a principios del siglo XVII los impresores españoles continuaban editando libros de caballería, hecho que viene a corroborar su perdurable demanda y popularidad. Véase el trabajo de Russell, P.E.: "The Last of the Spanish Chivalric Romances: Don Policisne de Boecia”, en Essays in Narrative Fiction in the Iberian Peninsula in Honour of Frank Pierce, Oxford, 1982, págs. 141-152.

19 Véase Torre Revello, J.: El libro, la imprenta y el periodismo en América durante la dominación hispana, Buenos Aires, 1940, pág. 125. 
que hemos identificado el Commentaria ad leges regias meliorationum de Andrés Angulo; en política, 5 de los Emblemas de Andreas Alciato; y en música, algunos tratados de canto. Por último, en el apartado de varios hemos incluido 58 libros de difícil identificación y que no cuadran en los capítulos anteriores, como 14 ejemplares de la Chronographía o repertorio de los tiempos de Jerónimo de Chaves, 3 de filosofía, 3 de moral, etc.

La literatura religiosa es un capítulo fundamental del inventario de Pedro Durango, que, conforme a los dictámenes de Trento, destaca en el género ascético-espiritual: 26 libros del Apocalypsim commentario de Francisco de Ribera, 8 de El modo de rezar el rosario de Gaspar de Astete, 6 de los Veynte discursos del credo... de Esteban de Salazar y 5 del Arte dada del mismo Dios a Abraham, para le servir perfectamente de Rodrigo de Solís. Llamativa resulta, por ser el autor de mayor eco en el mundo hispano, ${ }^{20}$ la corta cuantía de las obras de Fray Luis de Granada, tan sólo aparece con un ejemplar de su Introducción al símbolo de la fe; en la misma medida están las Cincuenta oraciones fúnebres... de Luis de Rebolledo, la Primera parte de las postrimerías del hombre de Pedro de Oña, la Segunda parte de la sylva espiritual de Antonio Álvarez y el Conptemptus mundi de Tomás de Kempis. ${ }^{21}$

La hagiografía incluye obras muy variadas, aunque no los títulos que nos son más familiares. ${ }^{22}$ Está el Flos sanctorum de Ribadeneyra, del mismo autor 2 de la Vida del padre Ignacio de Loyola; otros títulos son: Vida de Santo Domingo, Vida y muerte del apóstol San Pedro de Francisco Adame de Montemayor, Vida de San Francisco de Paula de Paolo Regio, Vida de Santa Leocadia de Miguel Hernández, etc. Vinculado a este tema, he incluido un apartado sobre Cristo y la Virgen, en el que figuran 7 del Retablo de la vida de Cristo de Juan de Padilla y 2 de la Universal redempción, passion, muerte y resurrección de Jesu Christo de Francisco Hernández Blasco. Cerrando el bloque religioso van autores de la escolástica como Tomás de Aquino y Tomasso Vío; el capítulo de varios con 5 libros de música religio-

20 Véase, para la literatura espiritual, Bataillon, M.: Erasmo y España, México, 1983.

21 Para la identificación de la literatura devocional me ha sido muy útil el trabajo de Álvarez Santaló, L.C.: "Adoctrinamiento y devoción en las bibliotecas sevillanas del siglo XVIII", en La religiosidad popular, Barcelona, 1989, vol. 2, págs. 21-45.

22 Nos ha sido de una gran ayuda para la identificación de las vidas de santos el repertorio de Simón Díaz, José: "Hagiografías individuales publicadas en español de 1480 a 1700", Hispania Sacra, 30, Madrid, 1977, págs. 421-480. Debo llamar la atención sobre las dificultades que entraña identificar este género librario, dada la multitud de obras que circulaban con títulos muy parecidos; pero, aun siendo consciente de un alto margen de error, he preferido hacerlo en función de los datos contenidos en los inventarios y cuando ha sido posible. 
sa, la Biblia, la Summa conciliorum de Bartolomé de Carranza, el Adversus omnes haereses de Alfonso de Castro e, incluso, uno del Corán.

El inventario de Cristóbal Hernández presenta una gama mayor de literatura religiosa; pero, al igual que en la mercancía de Pedro Durango, el género ascético-espiritual acapara las preferencias. Se trata de un apartado muy diverso, en el que esta vez sí es fray Luis de Granada el autor más representativo con 121 ejemplares del Libro de la oración y meditación. Le siguen 73 del Devocionario de Jacome Carvallo, 64 de la epopeya religiosa de Diego de Hojeda la Cristiada, escrita en Perú, 26 de la Perfección religiosa de Arriaga, 13 de las Meditaciones de la vida de Nuestra Señora de Francisco Costero; de Cristóbal de Fonseca 42 de los Discursos para los santos del evangelio de la Cuaresma y 13 del Tratado del amor de Dios; 12 de la Razón del pecado original y 9 de la Primera parte del consuelo de justos de Pedro Maldonado. Este último autor también registra varios ejemplares de Ejercicios para un oratorio; todas estas obras representan en conjunto más del $70 \%$ del capítulo.

No podemos dejar de hacer mención de algunos autores, de amplia difusión durante los siglos XVI y XVII, constatados en el documento, tales como: Antonio Álvarez, Juan de Dueñas, Alberto Magno, Fray Luis de León, Pedro Calderón, Diego de Estella, Pedro de Oña y, siendo curioso para las fechas de los inventarios, Erasmo con 2 ejemplares del Enchiridion. ${ }^{23}$

Lo abultado del capítulo dedicado a pastoral, derivado de la demanda del clero para llevar a cabo la evangelización de los indios, se debe a la inclusión de 113 catecismos en lengua española y quechua y 76 sólo en español. Lo mismo sucede con el de oración, en el que los 68 ejemplares del Modo de rezar el rosario... de Gaspar de Astete casi lo completan. En cambio, la hagiografía presenta 32 libros, eso sí, la Vida de Santa Teresa de Jesús de Francisco de Ribera cuenta con 24 ejemplares; los restantes, al estilo de los del inventario de Pedro Durango: Vida y milagros del glorioso San Antonio de Padua de Fray. Miguel Mestre, Historia de San Raimundo Peñafort de Vicente Miguel de Moradell, Vida de San Ildefonso, tal vez de Francisco Portocarrero; Vida de San Nicolás de Tolentino de Francisco de Ribera, Vida de San Román, Vida y martirio de Santa Inés de Eugenio Martínez, Historia de milagros, éxtasis y revelaciones, etc. Menor proporción acaparan los libros sobre Cristo y la Virgen, con títulos como: 5 de la

23 Para estos géneros también es muy útil el libro de Andrés, M.: Los recogidos. Nueva visión de la mística española (1500-1700), Madrid, 1976. 
Asunción de Nuestra Señora de Francisco de Toledo, La vida del dulcísimo Jesús, De la llegada de Cristo, etc.

Los temas bíblicos aparecen entre los principales de la clasificación temática, pero la diversidad no es mucha, pues 46 ejemplares corresponden a un libro de Salmos y casi todo lo demás a Evangelios. De los apartados restantes, en teología moral sobresalen 5 del Summario de confesores y penitentes de Martín de Azpilcueta, 3 del Tratado de casos de conciencia de Antonio de Córdoba, 2 de la Summa summularum de Gaspar Cardillo y las de Peraza, Ledesma, Mercado y Toledo. Sermonarios aparecen el de Pedro Bejarano, Baltasar Arias, Peraza y Miguel Pérez; los 16 libros de la patrística son las Epístolas de San Jerónimo; en la escolástica, autores muy representativos como Domingo de Soto, Tomás de Aquino y Francisco de Vitoria; y en los cánones, el repertorio de Josephus Anglés. Al final, en varios, títulos como: Profecías, Tratado de religión y 17 de las Rimas sacras de Lope de Vega, autor de amplia presencia en la tienda de Cristóbal Hernández.

Por lo que respecta a la temática laica, de nuevo la literatura alcanza la primera posición, con un autor, y no es de extrañar, como estrella: 216 ejemplares de los Soliloquios y 3 del Isidro de Lope de Vega. La novela picaresca también está ampliamente representada, como suele suceder, con uno de sus mejores exponentes, concretamente 47 ejemplares de la segunda parte del Guzmán de Alfarache de Mateo Alemán. ${ }^{24} \mathrm{Al}$ mismo tiempo figuran 24 de La Arcadia de Sannazzaro, una de las cumbres de la novela pastoril del Renacimiento; 12 del Viaje al Parnaso de Cervantes, 12 de Sonetos de Petrarca, 3 de Sonetos de Garcilaso y la Propalladia de Torres Naharro. ${ }^{25}$

Numéricamente, un capítulo importante dentro de los temas laicos es la gramática, aunque sus títulos no son muy diversos: 93 del Tesoro de la lengua aymara de Ludovico Vertonio, 54 del Vocabulario general de la lengua quechua, 44 de la Grammatica o arte de la lengua general de los indios de los Reynos del Perú. ${ }^{26}$ No está ausente Antonio de Nebrija con 5 ejempla-

24 Según Leonard estos géneros se imponen en los gustos lectores a medida que decaen los libros de caballería: Los libros..., pág. 255.

25 Sobre la importancia de las creaciones de la literatura del Siglo de Oro español en las bibliotecas coloniales es importante el trabajo de Hampe, T.: "El eco de los ingenios: literatura española del Siglo de Oro en las bibliotecas y librerías del Perú colonial”, Histórica, XVI, Lima, 1992, págs. 177-201.

26 Estas son obras directamente vinculadas a la labor misional, para la comunicación entre españoles e indios. Sobre la cuestión no debemos dejar de mencionar el trabajo de Hampe, T: "Lexicografía y cultura. Diccionarios de lenguas europeas e indígenas en las bibliotecas del Perú colonial (siglos XVI-XVII)", en Langues et cultures en Amérique Espagnole Colonial, París, 1993, págs. 75-101. 
res del Arte de la lengua castellana. Otra cuantía considerable alcanzan los clásicos grecolatinos y, como suele ocurrir, el documento sólo registra autores y no títulos, de este modo van 20 libros de Terencio, Plinio, César, Aristóteles, Cicerón, Séneca, Virgilio, Marco Aurelio, Horacio y Esopo. ${ }^{27}$ Con un buen repertorio sigue la historia: 5 de la Historia de España de Mariana, junto a obras como Las Navas de Tolosa, Historia de Etiopía, Historia de Francia, Historia de China, Historia de Cataluña, Historia de la reina de Saba y la Historia eclesiástica de los cismas de Inglaterra de Ribadeneyra. En ciencia otra vez es la medicina el capítulo central, con la conocidísima Cirujía de Fragoso y la de Hidalgo. Por último sólo quedan por mencionar 4 ejemplares del vocabulario jurídico de Nebrija.

\section{Advertencia final}

De la estructura temática que acabamos de analizar podemos deducir una conclusión ingenua: hay mayor cantidad de libros laicos porque se vendían más; sin embargo, estaríamos cometiendo un error. El estado actual de nuestros conocimientos nos pone de relieve un predominio casi absoluto de los libros de carácter religioso, no siendo de extrañar si tenemos presente los patrones de conducta de la sociedad hispana de los siglos XVI y XVII, ${ }^{28}$ período de tiempo en el que la lectura era un ejercicio espiritual, una actividad sagrada que resolvía misterios. ${ }^{29}$ Lo cual nos lleva a no perder de vista que un inventario, incluso si es de un mercader, no es más que una instantánea de un momento muy concreto, del que no se deben extraer, a menos que queramos distorsionar la realidad, afirmaciones tajantes ni definitivas. En estos casos, la mercancía puede ser resultado de una coyuntura determinante: los libros no vendidos hasta el momento de la muerte del titular, las existencias de los núcleos de abastecimiento, etc.

Lo anterior no quita importancia a la extendida demanda de literatura laica, que realmente existió, ni a la popularidad de los géneros de ficción a lo largo de la Edad Moderna; pero el hecho de ser este tipo de libros minori-

27 Sobre el tema es fundamental el magnífico trabajo de Gil, J.: "El libro greco-latino y su influjo en Indias", en Homenaje a Enrique Segura Covarsi, Bernardo Muñoz Sánchez y Ricardo Puente Broncano, Badajoz, 1986, págs. 61-111.

28 Véase Caro Baroja, J.: Las formas complejas de la vida religiosa (siglos XVI y XVII), Madrid, 1985. De Christian, W.A.: Local religion in sixteenth-century Spain, New Jersey, 1981, y Apparitions in late Medieval and Renaissance Spain, New Jersey, 1981.

29 Darnton, R.: "Historia de la lectura", en P. Burke (ed.): Formas de hacer historia, Madrid, 1994, págs. 177-208. 
tarios en los inventarios particulares estudiados y, por el contrario, de una presencia considerable, aunque inferior a lo religioso, en los registros de los mercaderes nos da pie para plantear algunas hipótesis. En primer lugar, advertir, como lo hiciera T. Hampe, que gran parte de las comedias y novelas cortas de la época circulaban en pliegos manuscritos y, por ello, no suelen dejar rastros en los inventarios de bibliotecas. ${ }^{30}$ Por otro lado, la mayor parte de los inventarios de bienes disponibles corresponden a grupos socioprofesionales de cierta formación intelectual y solvencia económica, ${ }^{31}$ con un claro protagonismo de clérigos, funcionarios y profesiones liberales; en menor medida, artesanos y mercaderes. De tal modo que el ejercicio profesional condiciona en gran medida la estructura temática de las bibliotecas. En cambio, tomar como argumento el amplio margen del analfabetismo no sería una razón de peso, dada la importancia en la época de la lectura en voz alta y dirigida a más de una persona, práctica bastante generalizada e ideal para los libros de aventuras, vidas de santos y todo tipo de literatura didáctico-moralizante. ${ }^{32}$ En cambio, la lectura como experiencia privada era de minorías, ${ }^{33}$ pero, atendiendo a los planteamientos de $\mathrm{B}$. W. Ife, el número de lectores solitarios de literatura de ficción en prosa y en lengua vernácula experimentó un notable incremento en la España del Siglo de Oro. ${ }^{34}$

Sirva, pues, este trabajo como pequeña aportación a un tema complejo, necesitado de investigadores, nuevas fuentes y métodos; pero imprescindible si queremos llegar a conocer una mínima parte de las inquietudes culturales de la sociedad colonial, a modo de introducción a sus actitudes, conductas, creencias y aspiraciones.

30 Hampe: "El eco de los ingenios...".

31 Remitimos a la bibliografía citada a lo largo de este trabajo. También a Solano, F. de: "Fuentes para la historia cultural: libros y bibliotecas de la América colonial", en Ensayos de metodología histórica en el campo americanista, Madrid, 1985, págs. 69-84.

32 Sobre la lectura en voz alta durante la Edad Moderna es muy sugerente el libro de Chartier, R.: El mundo como representación. Historia cultural: entre práctica y representación, Barcelona, 1992, págs. 121-145.

33 Darnton, "Historia de la lectura".

34 Ife, B. W.: Lectura y ficción en el Siglo de Oro. Las razones de la picaresca, Barcelona, 1991, pág. 7. 


\section{Apéndice}

\section{INVENTARIO DE LOS LIBROS DE PEDRO DURANGO DE ESPINOSA.}

(AGI, CONTRATACIÓN, 273, R. ${ }^{\circ}$ 3)

- quinze libros de Florisel de Niquea

- seys libros de Palmerín de Oliva

- onze de la Historia del Reino de Nápoles

- quatro Amadís de Grecia

- ocho Crónicas del Rey Don Pedro

- nueve Don Florisel de Niquea

- veyntedos Riberas sobre Apocalipsis

- doze libros de tablas de la monarquía eclesiástica

- seys de Varones ilustres de Sedeño

- dos Guadalupes Ynoseas

- Ribera sobre el Apocalipsis

- dos Riberas del Apocalipsis

- Alfonso de Castro

- Soto de natura de gracia

- Obras de Moya

- diez Historias de Señoría

- Jardín de amores santos

- Flos sanctorum de Bilbao

- Historia general

- tres Ribera sobre los profetas

- Espejo de caballería

- Herrera sobre Escoto

- Santo Tomás sobre los Evangelios

- syete Amadís

- grande de España

- Primaleón

- quatro Sergas de Esplandián

- dos Controversias de Valle

- del dicho

- Torquinto
- Sacra filosofía de Valle

- tres Historias de señoría

- tres Caballeros de la Cruz

- Controversias de Valle

- quatro Historias de Nápoles

- tres Crónicas del Rey don Pedro

- dos Historias de Nápoles

- Comentarios de Aristóteles

- Orlando en prosa

- dos Historias de Nápoles

- quatro Monterias

- Suárez sobre San Lucas

- Símbolo de fray Luis

- Flos sanctorum de Ribadeneyra

- dos de Albeitaria

- dos Triunfos de Cristo

- de la República del mundo

- seys Retablos de la vida de Cristo

- los cinco libros de Ambrosio de Morales

- los Santos de España

- Pedro pretores

- tres Monterias

- dos Amadís

- Hanseni sobre los salmos

- Hanseni sobre las concordancias

- Sermones de San Agustín

- de las siete virtudes

- Orlando en prosa

- otro dicho

- Lógica cayetana

- nueve Historias troyanas

- quatro Historias de Nápoles 
- tres Palmerín de Oliva

- cinco Sergas de Esplandián

- de Castro

- dos Historias del rey don Rodrigo

- quatro Historia del gran capitán

- del salmos de música

- Diálogo de la verdad

- quatro Historia del rey don Jaime

- quatro Lisuarte

- tres Historia del rey don Alonso

- Orlando en prosa

- otro dicho

- Filosofía de Valle

- tres Historia de los reyes godos

- Ayora de partición

- tres Don Reinaldos

- Cayo Julio César

- Historia de Santo Domingo

- de Villalpando sobre leyes

- del viaje del rey don Felipe a Flandes

- Obras de Mesua

- Lógica cayetana

- Valles de medicina

- quatro Historia de medicina de Sevilla

- Lisuarte de Grecia

- del gran capitán

- Palmerín

- don Florisel

- Retablo de la vida de Cristo

- del rey don Pedro

- Sentencia de los Jirones por Gudiel

- Proverbios de Séneca en romance

- de los nueve de la fama

- de Gómez de León sobre las informaciones en derecho

- sesenta y un de Varones ilustres de Indias

- doze Floranís de Castilla

- seys de Joaquín Romero

- de dicho
- dos Historia de Mafei de la India

- dos Artes de Solís

- cinco Discursos morales

- dos Declaraciones del credo

- Silva de Alvarez

- dos de comedias de Cuevas

- dos Discursos sobre el credo

- otro dicho

- tres de militare

- de políticas de mujeres

- nueve de Carlos duque de Borgoña

- quatro de Selidón

- otro dicho

- dos de comedias de Cuevas

- otro dicho

- de Almonasir in cantica canticorum

- ocho de guerra de campaña de Roma

- tres Artes de servir a Dios de Solís

- de adoración de imágenes

- dos discursos de la lengua

- cinco Varones ilustres de Indias

- quatro Cancionero de Lope Maldonado

- dos Roncesvalles

- dos Capilla heremias

- cinco de verdadera e falsa profecía

- de adiciones de la bula

- Angulo de mejoras

- de San Raimundo

- dos de Jarifes

- dos de guerra de la campaña

- de Garetano de abima

- dos de re militare

- Historia de Inglaterra

- Historia de las Indias

- quatro de Bernardo del Carpio

- dos de cien novelas de Orlando

- de fray Luis de León sobre los altares

- dos discursos morales

- dos caballero Acisio 
- cortés caballeroso

- catálogo de los libros prohibidos

- dos Historia de los jarifes

- República de Aristóteles

- dos Repertorios de Chaves

- de Guevara

- dos del maestro Oliva

- Adagios de Pablo Manunzias

- dos de universal redención

- de vida y muerte de san Pedro

- de la batalla de Naval corte real

- del excelente capitán

- libro de cantos de Mata

- discurso del credo

- Orlando furioso

- quatro apuntamientos

- vida de Proquinto

- República de Aristóteles

- capilla heremias

- Orlando enamorado

- Declaraciones de Orozco

- nacimiento de Orlando

- Orlando enamorado

- dos del caballero enamorado

- Acosta de drogas

- obras de Monardes

- Suma conciliorum

- de Angeli sangrini

- de Ovando

- de cayo lisigoni

- Diego Zúñiga

- ordo canonicorum

- de consejos de lopime

- República de Aristóteles

- de Ovidio comentado

- Suma silvestrina

- Acosta de drogas

- de glosas de Padilla

- dos de corán de Mahoma

- León Baptista de arquitectura

- estaciones del cristiano

- dos Lusiadas de Camues
- dos de Selidón de Iberia

- tres de clericorum

- dos caballero Acisio

- oraciones fúnebres de Rebolledo

- Ambrosio laterino

- Araucana

- otra dicha

- Repertorio de Chaves

- quistonario de cámara

- postrimerías del hombre

- estado del matrimonio

- concilio sacra escritura

- del cortés caballeroso

- comedias de Cuevas

- de la naturaleza del caballo

- Obras del maestro Oliva

- Apiano alejandrino

- de cantos de Mata

- jumetría de Oclides

- de Selidón

- Repertorio de Chaves

- historia de los jarifes

- Orlando enamorado

- Acosta de drogas

- Concordia de las dos leyes

- de santa florentina

- sesenta y nueve libros de historias

- Imitación de Cristo

- Biblia sacra

- Anglés sobre el cuarto de la sentencia

- quarenta y ocho artes de Antonio

- dos pasio duorum

- quatro diretorum curatorum

- seys de cuarenta cantos

- libro de Osuna

- vida de san Francisco de Padua

- entretenimiento de damas y galanes

- dos de la vida del padre Ignacio

- quatro de Lucano

- tres emblemas de Alciato

- dos del regidor ciudadano 
- doze libros de Isabel reina de Inglaterre

- quatro de santa Leocadia

- tres de monserrate

- dos fábulas de Ysopo
- ducientos setenta y seys libros de historias

- ocho astetes

- ducientos quarenta libros de historia, algunos sin encuadernar

\section{INVENTARIO DE LOS LIBROS DE CRISTÓBAL HERNÁNDEZ GALEAS (AGI, CONTRATACIÓN, 345A, R. ${ }^{\circ} 11$ )}

- trenyta y tres cuaresmas de Fonseca

- treynta y quatro vocabularios de la lengua deste reyno arte nueva

- dos de lo dicho

- otro de lo dicho

- treynta y cinco cristiadas del padre ojeda

- advertencias de la historia de Mariana

- cristiada de hojeda

- historia de Etiopía

- santoral de Arias

- gobierno eclesiático de fray Gregorio de Alfaro

- agricultura de Herrera

- obra de castillejo

- tratados de amor de Dios por Fonseca

- gobierno eclesiástico por alfaro

- Juan Alonso Garrotillo

- diez privilegios para mujeres preñadas por el doctor Juan Alonso

- las Navas de Tolosa

- consul Augusto por fray Pedro Maldonado

- práctica de una religiosa por Pedro Calderón

- navegación segura para el cielo de fray Gerónimo de Segorbe

- la madre Teresa de Jesús
- essequias del rey Philippo segundo

- tesoro de la lengua aymara por el padre Ludovico Vertonio

- otro dicho

- España defendida de Cristóbal Suárez de Figueroa

- escelencias de la castidad por fray Josephe de Jesús

- Avila de sacramento

- Hidalgo de cirujía

- Salmerón

- consul Augusto de Maldonado

- de la madre Teresa de Jesús

- catorce discursos sobre la oración del padre nuestro de fray Baltasar Pacheco

- reisersión de Africa

- ejercicios de un oratorio por fray Pedro Maldonado

- omiliario evangélico por Juan Bautista Madrigal

- Guzmán de Alfarache

- consuelo de justos por Maldonado

- de los nombres de Cristo por fray Luis de León

- de la madre Teresa de Jesús

- agricultura de Herrera y la historia de san Raimundo

- cristiada de ojeda 
- declaración de los siete salmos penitenciales

- Epístolas de san Jerónimo

- arte de la lengua general deste reyno

- declaración de los salmos penitenciales

- prado espiritual

- consideraciones de las amenazas del juicio por Alonso de Herrera

- otro dicho

- de la vanidad del mundo de Estella

- Teresa de Jesús

- Arte de servir a Dios

- de la guerra de campaña de Roma

- juridición cristiana por fray José Luquián

- de la conservación de la salud del cuerpo y del alma

- parnaso antártico por Diego Mejía

- Fragoso de cirujía

- Monarquía eclesiástica por Pineda

- Cuaresma de Fonseca

- noche del alma

- jerarquía eclesiástica

- virtudes de piedras

- sonetos de Petrarca

- obras de Garcilaso

- Monserrate de ejecuciones de bienes

- Guzmán de Alfarache

- Tratado del amor de Dios de Fonseca

- Avila de sacramento

- evangelios de la cuaresma de fray Alonso de Guevara

- práctica espiritual de una religiosa por el padre Calderón

- vocabulario general de la lengua quechua

- Guzmán de Alfarache

- sermones en fiestas de algunos santos por Bexarano
- de la madre Teresa de Jesús por Ribera

- vocabulario de la lengua quechua

- Guzmán de Alfarache

- otro dicho

- de las postrimerías del hombre

- del nacimiento de san Juan bautista

- Demostraciones católicas

- arte de la lengua quechua

- dos libros intitulados de la desención de nuestra señora de Toledo

- tres de la lengua quechua

- fiel desengaño portugués

- de la lengua quechua

- sucesos de las Filipinas

- Cristiada

- Silva de Alvarez

- historia de Francisco Guichardino por Flores

- sumario de cuentas de plata y oro destos reynos

- Rimas sacras de Lope

- dos del Guzmán de Alfarache

- historia de Cataluña por Bernardo Desclot

- Guzmán de Alfarache

- advertencias a la historia de Mariana

- de la madre Teresa de Jesús

- otro dicho

- discursos predicables por fray Baltasar Arias

- Emblemas morales de Juan de Orozco

- Herrera de amenazas del juicio

- fiel desengaño por Francisco Luque

- de la lengua quechua

- Cristiada

- otro dicho

- guzmán de Alfarache

- dos libros de lo dicho

- de la lengua quechua

- Terencio 
- la tradución del Yndia de los tres diálogos

- Suma de Ledesma

- del segundo por Avila

- de las amenazas del juicio

- de la lengua quechua

- parnaso antártico por Mejía

- de la madre Teresa de Jesús

- dos del Guzmán

- vida y milagros de san Antonio de Padua

- Cuaresma de Fonseca

- de la madre Teresa de Jesús

- de la lengua quechua

- Cuaresma de Fonseca

- Cristiada

- dos de la lengua quechua

- vida de san raimundo

- apuntamientos de todos los semones

- Cuaresma de Fonseca

- Cristiada

- Guzmán de Alfarache

- Terencio en latín

- de la lengua quechua

- el solitario poeta

- santoral de Arias

- Francisco Patricio por el gobierno

- arte quechua

- años del juego

- Guzmán de Alfarache

- ejercicios de un oratorio

- suma y compendio de los grados de la oración

- arte quechua

- Cristiada

- Guzmán de Alfarache

- Rimas sacras de Lope

- Cristiada

- vocabulario de la lengua general

- lengua quechua

- Murcia de lógicas

- Osorio eclesiástico
- quatro libros de la Cristiada

- ejercicios de un oratorio

- espejo de perfeción

- sonetos de Petrarca

- Angélica de Soto

- devoción de consolación

- Cuaresma de Fonseca

- Cristiada

- Guzmán de Alfarache

- dos libros de la Cristiada

- una disputa de la llaga de Cristo

- consolación de nuestra señora

- historia de la verdadera

- arte quechua

- quarenta y quatro de la esposición de los polbano

- monarquía eclesiástica y terrena

- arte y ejercicio de la oración

- condición cristiana

- arte quechua

- Guzmán de Alfarache

- de la madre santa Teresa de Jesús

- (Ilegible)

- las Navas de Tolosa

- diálogos de la naturaleza del hombre

- tesoro de consejos divinos

- Guzmán de Alfarache

- santa Juana de la Cruz

- Garcilaso

- perfeción religiosa

- tragedias de amor

- vida del padre fray Nicolás Fajón

- arte quechua

- dos del Guzmán

- Amenazas del juicio

- arte quechua

- Cristiada

- del bien y obligaciones del estado criminal

- discursos sobre el padre nuestro

- las fiestas de san Ramón 
- Suma de tratos contratos

- ciento y trece catecismos en español y quechua

- arte quechua

- Guzmán de Alfarache

- cinco de la lengua quechua

- cient y diesisiete libros de oraciones y ejercicios de fray Luis de Granada

- ochenta y seys libros de la lengua aymara

- sesentayquatro libros de nuestra señora de Gaspar de Astete

- setentaytres libros de devocionarios y relicarios por Jacome Carvallo

- nueve libros de oras devotissimas de Ortiz Luzio

- cuatro libros del perfecto cristiano de fray Juan González

- seys libros de meditaciones de nuestra señora de Costero

- desengaño de la vida de fray Julián Martel

- de la campaña de Roma

- vida de san Jacinto

- Sylva de la providencia de Dios

- Plinio de animales traducido

- Guzmán de Alfarache

- dieciseys docenas de soliloquios de Lope

- Plinio de pescadores

- dos libros del Guzmán de Alfarache

- tesoro de misericordia divina

- obras de Astete

- historia de san Bernardo por Vicente Miguel

- Guzmán de Alfarache

- San Onorio y Estacio patronos de Jerez de la frontera

- Cristiada

- consideraciones del agradecimiento cristiano por González

- Guzmán de Alfarache
- de la madre Teresa de Jesús

- historias de Francia de Herrera

- comercio terrestre

- Guzmán de Alfarache

- de santa Teresa de Jesús

- patronos de Jerez

- de santa Teresa

- condición cristiana de Luquián

- consuelo de justos

- tres libros del Guzmán

- práctica espiritual de Pedro Calderón

- lengua aymara

- Rimas sacras

- comentarios y salmos

- lengua quechua

- razón del pecado original

- dos libros de la lengua quechua

- Dionisio cartujo

- Plinio

- Confesionario

- Cristiada

- santos patronos de Jerez

- arte de la lengua del Perú

- otro de lo dicho

- consuelo de justos

- de la madre santa Teresa

- sobre la muerte de doña Luisa de Carvajal

- espositio titulorum

- tragedias de amor por Solorzano

- práctica espiritual

- meditación de la vida de nuestra señora por Costero

- la vida del dulsísimo Jesús

- filosofía natural

- tratado de los casos de conciencia por Córdoba

- fiestas a la beatificación de san Ignacio

- Guzmán de Alfarache

- sylva espiritual de Alvarez 
- soliloquio de San Buenaventura por fray Alonso ponce

- César

- flosculos clericorum

- la congregación de nuestra señora por Costero

- perfeción religiosa de Arriaga

- otro como el dicho

- tratado de la oración mental por Molina

- espejo de perfesión por Rojas

- manual de buenas meditaciones por Amaya

- del nombre de Jesús

- ejercicio de un notario

- perfesión religiosa

- instrusiones cristianas

- vida y milagros de san Raimundo

- Guzmán

- cuadernillo del rezo

- oficio del sensión de nuestra señora y vida de san Ildefonso

- fiel desengaño de Francisco Luque

- Rimas sacras

- perfesión religiosa

- espejo de perfesión

- otro como el dicho

- de la moneda y valor del oro

- elocuencia española

- Terencio en latín

- Angélica de Barahona

- ejercitatorio del padre Serna

- de adviento del padre Acosta

- un breviario romano

- cánones del consilio por Francisco Bartolomé

- espejo de consolación

- sermones en fiestas de santos por Bejarano

- instituciones caldaice

- tabla de casos notables

- Pacheco del segundo mandamiento
- institución confesorum

- ética de Aristóteles en latín

- de oratore

- práctica espiritual

- ejercicios divinos por Custodio

- manual del cristiano por Antonio Torres

- ejercicios divinos

- paraiso del alma

- diálogos de apacibles entretenimientos por Gaspar Lucas Hidalgo

- tres libros del arte quechua

- essequias de Philippo segundo

- de la vida de santa Teresa

- Cristiada

- de los nombres de Cristo

- sermones de adviento por Peraza

- siete libros de la lengua quechua

- dos libros de la Cristiada

- dos libros de santa Teresa

- sermones de los santos por fray Miguel Pérez

- consideraciones de los evangelios de Cabrera

- casos de conciencia por Córdoba

- advertencias de Mariana

- patronos de Jerez

- dos libros del Guzmán de Alfarache

- quatro libros de la lengua quechua

- Guzmán de Alfarache

- aziomata cristiana

- Cristiada

- ejercicios de un oratorio

- cuaresma de Fonseca

- de la fiesta de san Ignacio

- salmo pinciano

- Quaresma de Pedraza

- tres libros de santa Teresa

- dos libros del Guzmán de Alfarache

- exposisión sobre el salmo quarenta y quatro

- jerarquías eclesiáticas 
- consuelo de justos

- Cuaresma de Fonseca

- trato de religión y principio cristiano

- práctica espiritual

- confesionario para indios

- consuelo de justos por Maldonado

- tesoro de la verdadera cirujía

- de principio por Asyrolo

- Cristiada

- advertencia de la historia de Mariana

- consuelo de justos

- Pelayo

- de la madre santa Teresa

- figura bibliorum

- santa Juana de la Cruz

- Epístolas de Cicerón

- Suma in artículo mortis

- Epístolas de san Jerónimo

- dos libros del consuelo de justos

- Siglo de oro

- naufragio de Vitoria

- Epítomes epitetorum

- Suma artículo mortis

- Epístolas de san Jerónimo

- de la lengua quechua

- calendario perpetuo

- sermonario

- viaticum novum

- ejercicios de un oratorio

- historia de la reina de saba

- consuelo de justos

- Suma de casos de conciencia por Peraza

- de Isabel

- Terencio

- Propalladia de Naharro

- Rimas sacras de Lope

- Nicolao Serari

- in sapere util en toscano

- espejo de perfesión
- doctrina moral de Lucio Arinco

- Suma de Villalpando

- comentari micaeli

- Tomé de Vio

- Enchiridion de Erasmi

- martirio de santa Inés

- Terencio

- aserciones luteranas

- Cicerón

- desengaño de fortuna

- Epístolas de san Jerónimo

- Terencio

- pecado original

- de la perfesión religiosa

- otro como el dicho

- Cristiada

- advertencias de Mariana

- del amante de doña Luisa de Carvajal

- lunario perpetuo

- de santa Teresa

- conquista de la Bética

- Rimas sacras

- Cristiada

- ninfas y pastores de Henares

- la fuente deseada

- Isidro de Lope

- passio duorum

- dos libros práctica espiritual

- las Navas de Tolosa

- vergel de plantas divinas

- Terencio

- Honras de doña Luisa de Carvajal

- meditaciones de nuestra señora

- quatro libros confesionarios de lengua inca

- tratado del estado matrimonial

- casos de conciencia de Córdoba

- de la lengua quechua

- utilitate legendi ystoria

- Cristiada

- Alejandro Farnesio 
- Cristiada

- del Guzmán de Alfarache

- divina poesía

- perfesión religiosa

- primera parte de santo Tomás

- vida de santidad

- milagros de santa Francisca romana

- Suma de Villalpando

- perfesión religiosa

- racione disendi

- suma cayetani

- patroni alamantino

- siglo del oro

- discursos de ynfabili berbi

- tragedias de amor

- Epístolas de san Jerónimo

- novum Yesucristite

- meditaciones de nuestra señora

- arte de servir a Dios

- razón del pecado original

- espejo de perfeción

- dos libros del compendio de Navarro

- salutei oraciones

- Garcilasso

- ystoria del nuevo mexico

- tesoro de consetos

- dos de Terencio

- razón del pecado original

- rimas sacras

- Terencio

- un enchiridion

- de la llaga de Cristo

- un Ysrael liberada

- arte viejo

- viaje al parnaso

- Epístolas de san Jerónimo

- Epístolas de san Pablo

- ortografía castellana

- oraciones y ejercicios

- de la congregación de nuestra señora
- del modo de rezar el rosario

- diez libros de la perfesión religiosa

- Guzmán de Alfarache

- libro de cinco mártires por Francisco de Venecia

- dos artes de la lengua aymara

- comentari yn salmis

- ystoria de milagros esstasis y rebelaciones

- Bitorio delsimismo

- oraciones de universal eclesia

- un Julio César

- ystoria de la reyna de Saba

- Bitorio delsimismo

- guadalume ynosica

- quartus tomus cenciones de tempore

- Osorio de gloria

- arauco domado segunda parte

- un catecismo de dotrina cristiana

- sensión de nuestra señora y vida de san Ildefonso

- Séneca

- segundo tomo de Cicerón

- omilia y nonia

- de la lengua quechua

- tessoro de misericordias

- purificador de la consencia

- Rimas sacras

- de vita religiosa instituenda

- un catechismo en nuestra lengua

- triunfos de la fe en Japón

- Cabrera de yn re patronatibus

- de las partes de la oración

- de san Ignacio

- razón del pecado original

- Rimas sacras

- santidad y milagros de santa Francisca

- dos libros como el dicho

- de la muerte de doña luisa de Carvajal

- confisionario de quras de yndios 
- el modo de rezar el rosario

- de la vida, milagros esstasis y rebelaciones

- un arte de servir a Dios

- Marco Aurelio

- espejo de perfesión

- introducción yn dialeticam

- Epístolas de san Jerónimo

- essamen de sirujía

- propiedades de las piedras preciosas

- thessoro de consetos

- rimas sacras de Lope

- otro como el dicho

- Terencio

- arte de la lengua del Pirú

- abiso para soldados

- ystoria de Barlaan y Josafat

- esposisio oficio divino

- vida de santa Francisca

- quaresma de gazo

- quaresma de Fonseca

- demostraciones católicas

- tabula de sermones

- grabrielis paliose

- rimas sacras de Lope

- la vida de Fernando de Abalo

- lendibaresi

- el Pelayo

- de vita y pasiones altoris

- tratado de virtudes

- un libro de mano

- la fuente deseada

- alegrías de damas

- arte de la lengua quechua

- de la perfesión religiosa

- primera parte de Sagunto

- la suma de Toledo

- catesismo español

- tabulas generales escoti fe subtilitate

- segundo del pícaro

- fray Nicolás faetor
- Terencio

- diálogos de apasible entretenimiento

- Epístolas de Siserón

- epíteta

- rimas sacras de Lope

- razón del pecado original

- Epístolas de san Jerónimo

- Epístolas de Siserón

- thesoro de misericordia

- deboto viaje de la tierra sancta por fray Pedro de santo Domingo

- san Raymundo Peñaflor

- prontuarium catolicorum

- compendio Navarri

- doctrina de fray Luis

- Terencio

- sensiones yn ebangelie

- de vita et lau dibinis dey

- questiones de Siserón

- misal de las epístolas de Lusio

- arte de servir a Dios

- arte de Antonio

- la bella cotalda

- diálogos viejos

- vita santorum brebi

- el solitario poeta

- tibi geronimi tridonensio

- segunda del pícaro

- vida de santa francisca

- de la lengua aymara

- norte del alma

- de exerctacio demostraciones

- dotrina de fray Luis

- Rimas sacras

- razón del pecado original

- oraciones de Siserón

- profesias en latín

- Terencio

- sancti Tomé

- jigas pincianibus

- Justino ystorias

- segunda del pícaro 
- otro como el dicho

- de castidad por Diego Pérez

- santos patronos de Jerez

- epístolas de san Jerónimo

- de la castidad

- Terencio

- razón del pecado original

- controversia yudi sisteme por Navarro

- santo Tomé

- rimas sacras

- vocabulario juris

- comentario devoto por P. ${ }^{\circ}$ Ortiz

- juanis feris esplicasión salmum trixe

- un monserrate

- Antonio broy quator evangelio

- calendario perpetuo

- fiestas a san Ygnacio

- dialética predigmata

- Luis Vives en latín y ejercicio de un oratorio

- comentario de Sesar en toscano

- comentario in salmis de maldonado

- del pecado original

- salucio oraciones

- dos libros de epístolas de san Jerónimo

- santos de Jerez

- filosofía

- perfesión religiosa

- tres catecismos en español

- logicarum terminorum aecio

- arte de servir a Dios

- del sisma de Inglaterra

- santa misteria pasio resurretio

- de verborum

- epístolas de Siserón

- comentario y rimas cum et lucam evangelista

- un sermonario

- sobre los signos

- otro del pícaro
- comentari de penitencie

- sobre los mandamientos

- pauli egineta

- almi florentissime

- suma de eclesie domine

- Juan de turrecremata

- logica de Valera

- vita regulari

- de oña

- ystoria del mundo toscano

- dies omiliarum super noben berbis salmi sinquenta

- comentari in universa Aristótelis

- Petrarca de remedios

- Josef Acosta consiones in quadragessiman

- consionem profeti bitatibus

- aparatos latinis sermones

- questiones regulares en latín fray Melchor Rodríguez

- convionum sante dominice Acosta

- thesauris escriturarum

- libro de ánima

- fabula deescole

- theologicarum sententiarum

- yntroducio benbum

- gracia eficace de Ortiz

- porladori

- concilii tridentini

- congregacionis de nuestra señora

- laurentibali

- Virgilio en latín

- epístolas de Cicerón

- Limirno

- responso ad libilum ubara mundi

- comentarios de jubileos

- epístolas de Jerónimo

- segunda del pícaro

- Isidro

- grandez mexicana

- razón del pecado original

- catecismo español 
- compendi nabarris

- fábulas de Esopo

- fabulas del mismo

- apostolorum apostolicorum

- obsevaciones quedam yn nonaginta quinque ynnos

- catecismo español

- Jerónimo Ramírez de los niños de la guardia

- arte general del reyno del Perú

- Rimas sacras

- orali placti poemata

- catecismo español

- Cicerón en latín

- narraciones yn evangelia

- juanis rrabisi testoris

- de fronti yn yssun estudiosum por Fontana

- la madre Teresa

- tratado del estado de la religión

- ystoria de la China por Mendoza

- tratado del remedio de pobres

- proverbios morales

- manual de vida perfecta

- vida y milagros de San Nicolás tolentino

- epístolas de san Jerónimo

- segunda del pícaro

- catecismo español

- Luis Vives en latín

- epístolas de Séneca

- la madre Teresa

- pastor de filida

- catecismo español

- Rimas sacras

- vida de san Pedro Nolasco

- catecismo español

- paraiso del alma

- arte de lengua española

- otro como el dicho

- dos libros de Terencio en latín

- ejercicio divino
- Rimas sacras

- razón del pecado original

- catecismo español

- otros dos como el dicho

- perfesión religiosa

- Manuel Alvarez de gramática

- perfesión religiosa

- catecismo español

- Manuel Alvarez de gramática

- Terencio

- dos libros de la perfesión religiosa

- dos catecismos en lengua española

- areopagitice

- quatro catecismos en lengua española

- perfesión religiosa

- confesionario y desengaño de simismo

- un Costero

- quatro catecismos español

- otros tres

- otros dos

- essamen de sirujía

- dos de la perfesión religiosa

- seys catecismos español

- dos docenas de soliloquios de Lope

- dos docenas de libros de la arcadia por enquadernar

- quatro catecismos español

- Luis Vives en latín

- veynte y ocho catecismos en español

- arte de servir a Dios

- Terencio

- oficia santorum hispani

- perfesión religiosa

- ejercicios divinos

- devoción y ejercicios

- epístolas de Siserón

- compendio de Navarro

- catecismo español

- tratado de confesión y absolución 
- seys catecismos español

- oraciones y ejercicios

- nuestra señora de Loreto

- cinco del santo sacramento del bautismo

- epístolas de san Jerónimo

- Terencio

- perfesión religiosa

- dos oraciones y ejercicios

- almida bulgata

- razón del pecado original

- proverbios morales

- Alvarez de gramática

- dos catecismos español

- meditaciones de nuestra señora

- perfesión religiosa

- tres como el dicho

- paraiso del alma

- dos dotrinas de fray Luis

- itinerario catolicum

- sermones de san Diego

- Quinto Curcio

- desengaño del siglo

- manual del cristiano

- arte de la lengua aymara

- constituciones apostólicas

- suma de Toledo

- perfesión religosa

- espejo de perfesión

- varia devoción en toscano

- arte de la lengua española

- dotrina religiosa

- viaje al parnaso de Cervantes

- compendio de Navarro

- quarenta y quatro libros naufragio de vitoria de la compañía de Jesús

- controversias de Navarro

- consilia abatiz

- optima predisendo rasione

- oras de nuestra señora

- epístolas de san Jerónimo en latín
- un mill y quatrocientas y ochenta estampas estrangeras de medio pliego

- un mill y ducientas y ochenta de dichas estampas de marca mayor

- un mill y ducientas ymagenes de pliego de marca mayor italiana

- mill y quatrosientas ymagenes de medio pliego de dicho género

- ducientos y veyntedos papeles grandes de a doce ymagenes

- siento sesenta y quatro papeles de a dos ymagenes

- siento y setenta y quatro papeles de a dos ymagenes

- ducientas ymagenes de todo género muy maltratadas

- trecientas y quatro rosarios negros

- mill y seicientas ymagenes de rosarios en ocho papeles atados

- quatrocientas echuras de cristos cruzificados pequeños de bronce para rosarios

- mill y ducientas de dichas estampas de marca mayor

- mill y ducientas ymagenes de pliego de marca mayor italianas

- mill quatrosientas ymagenes de medio pliego del dicho género

- ducientas veyntedos papeles grandes de a doce ymagenes

- siento sesenta y cuatro papeles de a dos ymagenes

- siento setenta y quatro papeles de a dos ymagenes

- ducientas ymagenes de todo género

- trecientos y quatro rosarios negros

- tres mill seyscientas ymagenes de rosarios en ocho papeles atados

- quatrocientas echuras de cristos cruzificados pequeños de bronces para rosarios 